\title{
Improved estimation of nitrogen uptake in grasslands using the nitrogen dilution curve - reply to the letter to the editor by Lemaire and Gastal, 2016
}

\author{
Julian J. Reyes ${ }^{1} \cdot$ Juergen Schellberg $^{2}$ - Stefan Siebert ${ }^{3}$ - Jennifer C. Adam ${ }^{1}$. \\ Martin Elsaesser $^{4}$ - Frank Ewert ${ }^{3}$
}

Published online: 9 September 2016

(C) INRA and Springer-Verlag France 2016

The critical nitrogen concentration (CNC) is a simple yet robust relationship that describes the changes in crop $\mathrm{N}$ during growth. In Reyes et al. (Agron Sustain Dev 35:15611570, 2015), we applied the concept of CNC to calculate N uptake across various cutting regimes. While it is wellestablished that decreasing cutting frequency changes growth rates, the parameters of the CNC equations may need to be adjusted based on the grass physiological age (i.e., vegetative versus reproductive stage). We do not question the validity of the $\mathrm{CNC}$ during vegetative growth; however, we recognize that there is research needed to test the effects of cutting date on composition and internal partitioning of $\mathrm{N}$ as it relates to the CNC. Moreover, we focus on the applicability of the $\mathrm{CNC}$ for use in process-based models for better understanding of the $\mathrm{CNC}$ for different crop ages and management considerations.

Keywords N dilution · Grasslands · Critical nitrogen concentration curve

Julian J. Reyes

julian.reyes@email.wsu.edu

1 Department of Civil and Environmental Engineering, Washington State University, PO Box 642910, Pullman, WA 99164-2910, USA

2 Institute of Crop Science and Resource Conservation, Agro- and Production Ecology, University of Bonn, Auf dem Hügel 6, D 53121 Bonn, Germany

3 Institute of Crop Science and Resource Conservation, Crop Science, University of Bonn, Katzenburgweg 5, D-53115 Bonn, Germany

4 Agricultural Center for Cattle Farming, Grassland Management, Dairy Processing, Wildlife and Fishery for Baden-Wuerttemberg, Wuerttemberg, Germany
We tested the critical nitrogen concentration curve (CNC) developed by Lemaire and Gastal (1997) for its validity and robustness under different cutting regimes on permanent grassland. The paper focuses on demonstrating the usefulness of the $\mathrm{N}$ dilution curve for a wider range of applications beyond current experimental research among various crops; such as in estimating plant $\mathrm{N}$ uptake for evaluation purposes in models that include $\mathrm{N}$ cycling. A large range of environmental and management conditions represented by datasets from central and southern Germany under various cutting regimes were included in our analysis. We calibrated the CNC and thereby considered the different physiological ages of grassland of different cutting frequency, i.e., two, three, and four cuts. We used subsets of these data to validate our curves. We concluded that the cutting regime data is required as additional information when calculating the $\mathrm{N}$ uptake for a wider range of grassland management based on the CNC.

We are very grateful for the critical arguments by the authors of the letter to the editor, who also developed the critical nitrogen concentration curve $(\mathrm{CNC})$, as they indicate a point in our paper which could be misinterpreted. The CNC is a simple, yet robust relationship with physiological meaning that can be reasonably integrated into process-based model routines to help determine crop $\mathrm{N}$ status, as long as equation parameters are adjusted to the effects caused by internal $\mathrm{N}$ partitioning (Devienne-Barret et al. 2000). Our procedure of calculating CNC takes account of the derivation of equation parameters apart from those that have been proven valid during vegetative growth on grassland. We were interested in how the dilution curve may vary under decreased cutting intervals which inevitably lead to longer growth duration between cuts. We specifically considered different physiological ages of grassland, including data from experiments where grassland was cut late in its development. 
It is well documented in the literature (Dahl and Hyder 1977) that decreasing cutting frequency alters growth rates (especially during re-growth) as well as floristic composition and morphological proportions of plants, such that tiller density decreases, leaf-stem ratio is reduced, and the contribution of $\mathrm{N}$ partitioning to total $\mathrm{N}$ utilization in metabolic processes of the crop increases. From these differences between early cut (at vegetative stage) and late cut (reproductive stage), it becomes clear that the parameters of the CNC function as described by Lemaire and Gastal (1997) need to be adjusted if applied to grassland of higher physiological age. Thus, we concluded that longer growth duration might also alter the $\mathrm{CNC}$ equation parameters, as indicated by Lemaire and Gastal (1997).

Figure 3a in our paper Reyes et al. (2015) indicates that critical $\mathrm{N}$ concentration decreases with decreasing cutting frequency. In other words, internal partitioning contributes significantly to above-ground biomass accumulation, mainly to the reproductive organs. This effect has been published for wheat already (Simpson et al. 1983), but to our knowledge not yet for multi-species grass swards. On the other hand, we are well aware of the fact that it is so far not recommended to apply the CNC concept for grassland beyond the early reproductive stage. In practice, however, grassland is often harvested much later than the vegetative phase, which needs to be accounted for in respective assessment studies. As such, simulation models need to be calibrated, validated, and applied for a wider range of management options and require a testing of the validity of the $\mathrm{CNC}$ concept for further use. Also, there is a scope for applications in remote sensing (Baret et al. 2007; Mistele and Schmidhalter 2008) and site specific management of grassland, which requires large-scale information on nitrogen status of crops including grassland of all phenological stages.

The results obtained from our study do not question the validity of the $\mathrm{CNC}$ approach during vegetative growth, which has been confirmed by many other studies already earlier (e.g., Bélanger et al. 2001; Ziadi et al. 2008). However, we recognize that only proper testing of the effects of cutting date on floristic composition and internal partitioning in a larger long-term fertilizer experiment following the approach published by Justes et al. (1994) would finally clarify the impact of crop age on $\mathrm{N}$ dilution, and thus also on parameters of the CNC. As long as such data are not available for grassland, we recommend adjusting $\mathrm{CNC}$ parameters as demonstrated in our paper.

\section{References}

Baret F, Houlès V, Guérif M (2007) Quantification of plant stress using remote sensing observations and crop models: the case of nitrogen management. J Exp Bot 58:869-880. doi:10.1093/jxb/erl231

Bélanger G, Walsh JR, Richards JE, et al. (2001) Critical nitrogen curve and nitrogen nutrition index for potato in eastern Canada. Am J Pot Res 78:355-364. doi:10.1007/BF02884344

Dahl BE, Hyder DN (1977) Developmental morphology and management implications. In: Sosebee RE (ed) Rangeland plant physiology. Society for Range Management, Denver, pp. 257-290

Devienne-Barret F, Justes E, Machet JM, Mary B (2000) Integrated control of nitrate uptake by crop growth rate and soil nitrate availability under field conditions. Annals of Botany 86:995-1005. doi:10.1006 /anbo.2000.1264

Justes E, Mary B, Meynard J-M, et al. (1994) Determination of a critical nitrogen dilution curve for winter wheat crops. Ann Bot 74:397407. doi:10.1006/anbo.1994.1133

Lemaire G, Gastal F (1997) N uptake and distribution in plant canopies. In: Lemaire $G$ (ed) Diagnosis of the nitrogen status in crops. Springer-Verlag, Berlin, pp. 3-43

Mistele B, Schmidhalter U (2008) Estimating the nitrogen nutrition index using spectral canopy reflectance measurements. Eur J Agron 29: 184-190. doi:10.1016/j.eja.2008.05.007

Reyes J, Schellberg J, Siebert S et al (2015) Improved estimation of nitrogen uptake in grasslands using the nitrogen dilution curve. Agron Sustain Dev 35:1561-1570, 2015. doi:10.1007/s13593015-0321-2

Simpson RJ, Lambers H, Dalling MJ (1983) Nitrogen redistribution during grain growth in wheat (Triticum aestivum L.) : IV. Development of a quantitative model of the translocation of nitrogen to the grain. Plant Physiol 71:7-14

Ziadi N, Brassard M, Belanger G, et al. (2008) Critical nitrogen curve and nitrogen nutrition index for corn in eastern Canada. Agron J 100: $271-276$ 